\title{
Critical weight loss in head and neck cancer-prevalence and risk factors at diagnosis: an explorative study
}

\author{
Harriët Jager-Wittenaar • Pieter U. Dijkstra • \\ Arjan Vissink • Bernard F. A. M. van der Laan • \\ Rob P. van Oort • Jan L. N. Roodenburg
}

Received: 27 June 2006 / Accepted: 20 December 2006 / Published online: 3 February 2007

(C) Springer-Verlag 2007

\begin{abstract}
Goals of work Critical weight loss ( $\geq 5 \%$ in 1 month or $\geq 10 \%$ in 6 months) is a common phenomenon in head and neck cancer patients. It is unknown which complaints are most strongly related to critical weight loss in head and neck cancer patients at the time of diagnosis. The aim of this explorative study was to assess the prevalence of critical weight loss and to analyze risk factors for critical weight loss in head and neck cancer patients before treatment.

Materials and methods Critical weight loss and factors reducing dietary intake were assessed in 447 patients referred to an ear, nose and throat clinic at the time of diagnosis.

Main results In total, data of 407 patients were analyzed. Critical weight loss was present in $19 \%$ of the patients. Patients with cancer in the hypopharynx, oropharynx/oral cavity and supraglottic larynx had the highest risk for
\end{abstract}

H. Jager-Wittenaar · P. U. Dijkstra • A. Vissink · R. P. van Oort J. L. N. Roodenburg

Department of Oral and Maxillofacial Surgery,

University Medical Center Groningen, University of Groningen,

P.O. Box 30001, 9700 RB Groningen, The Netherlands

\section{H. Jager-Wittenaar $(\bowtie)$}

Department of Dietetics, University Medical Center Groningen, University of Groningen,

P.O. Box 30001, 9700 RB Groningen, The Netherlands

e-mail: h.jager@fd.umcg.nl

\section{P. U. Dijkstra}

Department of Rehabilitation,

University Medical Center Groningen, University of Groningen,

P.O. Box 30001, 9700 RB Groningen, The Netherlands

B. F. A. M. van der Laan

Department of Otorhinolaryngology, Head and Neck Surgery, University Medical Center Groningen, University of Groningen, P.O. Box 30001, 9700 RB Groningen, The Netherlands critical weight loss. Loss of appetite, dysphagia/passage difficulties and loss of taste/aversion were significantly $(p<0.05)$ associated with critical weight loss.

Conclusions Already before treatment, critical weight loss is a considerable problem in head and neck cancer patients. Critical weight loss is frequently observed in patients with cancer in the hypopharynx, oropharynx/oral cavity and supraglottic larynx.

Keywords Weight loss · Malnutrition ·

Head and neck cancer · Prevalence $\cdot$ Risk factors

\section{Introduction}

Critical weight loss (CWL), defined as the involuntary weight loss of $\geq 5 \%$ in 1 month or $\geq 10 \%$ in 6 months, is a common phenomenon in head and neck cancer patients because it is present in about $30 \%$ to $55 \%$ of these patients $[5,17,19,28]$. CWL is clinically of utmost importance. It is associated with increased morbidity and mortality. CWL may result in an increased complication rate, such as impaired wound healing, reduced immune function and decreased tolerance to surgery, radiotherapy and chemotherapy $[2,25,28]$. CWL also reduces disease-related quality of life and functional status [27].

Head and neck cancer patients often experience complaints related to the localization of the tumor, such as dysphagia, odynophagia, passage difficulties and pain in the mouth $[6,7,9,10,18]$. Furthermore, systemic effects of the tumor may result in changes in taste or appetite $[15,22]$. These complaints may result in difficulties with nutritional intake leading to CWL. It is unknown, however, which complaints are most strongly related to CWL in head and neck cancer patients at the time of diagnosis. 
The aim of this explorative study was to assess the prevalence of CWL and to analyze the risk factors for CWL before treatment in head and neck cancer patients referred to the ear, nose and throat (ENT) department of the University Medical Center Groningen (UMCG).

\section{Materials and methods}

Patients with a newly diagnosed tumor in the head and neck region, either a (second) primary or a recurrent tumor, were screened according to the UMCG Head and Neck Clinical Screening Tool (UMCG H\&N CST) as a part of a routine clinical procedure at the ENT department of the UMCG. The screening was performed by an ENT physician or a nurse, at the first visit at the ENT department or at the time of endoscopic diagnostic investigation, usually about 2 weeks after the first visit.

The UMCG H\&N CST consisted of two parts. The first part assessed CWL, defined as weight loss of $\geq 5 \%$ in 1 month or $\geq 10 \%$ in 6 months $[1,2,4,8,25,28]$. Assessment of CWL was based upon the formula [normal weight $(\mathrm{kg})$-actual weight $(\mathrm{kg})] /$ normal weight $(\mathrm{kg}) \times$ $100 \%$ ]. CWL was recorded as a dichotomous variable (present/absent). The second part of the UMCG H\&N CST assessed symptoms that may lead to difficulties with nutritional intake, including loss of appetite, dysphagia, passage difficulties, pain in the throat, loss of taste/ aversion, dry mouth and pain in the mouth. These symptoms were recorded also dichotomously (present/ absent). In addition, tumor localization and tumor size of each patient were obtained from the medical records after diagnostics.

The data of 447 consecutive patients with a tumor in the head and neck region, screened between November 2001 and August 2004, were used for this study. For data analysis, SPSS version 12.0 (SPSS, Chicago) was used. Descriptive statistics were used to assess the prevalence of CWL. Stepwise multivariate logistic regression was used to identify risk factors for CWL. The presence or absence of CWL was used as the dependent variable, and the symptoms possibly influencing nutritional status were used as the independent variables. The influence of the tumor size (T) on CWL was calculated by means of chi-square analysis. A $p$ value $<0.05$ was considered statistically significant.

\section{Results}

Data of 407 patients out of 447 (91\%) of the UMCG H\&N CST were complete. Patient characteristics of patients with complete $(91 \%)$ and incomplete $(9 \%)$ data sets are summarised in Table 1. Significantly more patients with a tumor of hypopharynx, oropharynx/oral cavity or supraglottic larynx had an incomplete data set compared to patients with other tumor localizations $(p=0.038)$ and significantly more patients with a $\mathrm{T} 3$ or $\mathrm{T} 4$ tumor had an incomplete data set compared to patients with a $\mathrm{T} 1$ or $\mathrm{T} 2$ tumor ( $p=0.003)$. CWL was present in $19 \%(77 / 407)$ of the patients. Prevalence of CWL did not differ significantly between patients with a newly diagnosed primary tumor $(19 \%, 71 / 371 \mathrm{CWL})$ and patients with a recurrent tumor $(17 \%, 6 / 36 \mathrm{CWL})$.

Table 1 Patient characteristics

\begin{tabular}{|c|c|c|c|c|}
\hline \multirow{3}{*}{ 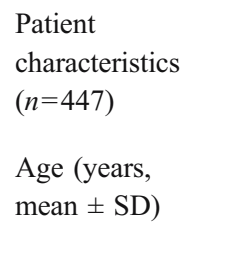 } & \multirow{2}{*}{\multicolumn{2}{|c|}{$\begin{array}{l}\text { Patients with } \\
\text { complete data } \\
(n=407) \\
63.3 \pm 13.8\end{array}$}} & \multirow{2}{*}{\multicolumn{2}{|c|}{$\begin{array}{l}\text { Patients with } \\
\text { incomplete data } \\
(n=40) \\
65.3 \pm 12.4\end{array}$}} \\
\hline & & & & \\
\hline & Percentage & Number & Percentage & Number \\
\hline \multicolumn{5}{|l|}{ Gender } \\
\hline Male & 74 & 302 & 80 & 32 \\
\hline Female & 26 & 105 & 20 & 8 \\
\hline \multicolumn{5}{|l|}{ Tumor type $\mathrm{a}^{\mathrm{a}}$} \\
\hline Primary tumor & 91 & 371 & 83 & 33 \\
\hline Recurrent tumor & 9 & 36 & 18 & 7 \\
\hline \multicolumn{5}{|c|}{ Tumor localization ${ }^{\mathrm{a}, \mathrm{b}}$} \\
\hline Larynx & 31 & 125 & 28 & 11 \\
\hline $\begin{array}{l}\text { Supraglottic } \\
\text { larynx }\end{array}$ & 9 & 38 & 13 & 5 \\
\hline Glottic larynx & 26 & 107 & 8 & 3 \\
\hline $\begin{array}{l}\text { Sub-/transglottic } \\
\text { larynx }\end{array}$ & 2 & 9 & 8 & 3 \\
\hline Oropharynx & 15 & 62 & 23 & 9 \\
\hline Hypopharynx & 12 & 49 & 20 & 8 \\
\hline Nasopharynx & 3 & 14 & 10 & 4 \\
\hline Oral cavity & 2 & 6 & 3 & 1 \\
\hline Other $^{\mathrm{c}}$ & 30 & 122 & 18 & 7 \\
\hline \multicolumn{5}{|l|}{ Tumor size $\mathrm{e}^{\mathrm{a}, \mathrm{d}}$} \\
\hline $\mathrm{T} 1$ & 20 & 82 & 13 & 5 \\
\hline $\mathrm{T} 2$ & 19 & 77 & 5 & 2 \\
\hline $\mathrm{T} 3$ & 8 & 32 & 18 & 7 \\
\hline $\mathrm{T} 4$ & 18 & 75 & 30 & 12 \\
\hline Not recorded ${ }^{\mathrm{e}}$ & 35 & 141 & 35 & 14 \\
\hline
\end{tabular}

${ }^{a}$ Total percentage is not similar to 100 due to rounding off. Percentages are column percentages.

${ }^{\mathrm{b}}$ Significantly more patients with a tumor of the hypopharynx, oropharynx/oral cavity or supraglottic larynx had an incomplete data set compared to patients with other tumor localizations $(p=0.038)$.

${ }^{\mathrm{c}}$ Carcinoma in the ear, salivary gland, nose/paranasal cavity, esophagus, thyroid gland, skin, eye, lymphoma and unknown primary.

${ }^{\mathrm{d}}$ Significantly more patients patients with a T3 or a T4 tumor had an incomplete data set compared to patients with a T1 or a T2 tumor $(p=0.003)$.

e From the tumors listed as 'other', no classifications of tumor size were made. 
Critical weight loss related to tumor localization

CWL related to tumor localization is presented in Table 2 . Tumor localizations in which CWL was present in more than $30 \%$ of the patients were the oropharynx/oral cavity, nasopharynx and hypopharynx. Although the prevalence of CWL in patients with laryngeal cancer was low $(12 \%$, 18/154), within this group of patients, patients with supraglottic laryngeal cancer had CWL more frequently (34\%, 13/38).

In total, 122 patients had a tumor at 1 of the following sites: ear, salivary gland, nose/paranasal cavity, esophagus, thyroid gland, skin, eye or lymphoma or had an unknown primary tumor. If this group of patients with tumor localizations registered as 'other' was excluded from the analysis, the prevalence of CWL increased to $24 \%(67 / 285)$.

Predictive symptoms for critical weight loss

Dysphagia and/or passage difficulties were most frequently reported in patients with hypopharyngeal cancer and the group of patients with cancer in the oropharynx/oral cavity (Table 3). Dysphagia and/or passage difficulties, loss of taste/aversion and loss of appetite were significantly associated $(p<0.05$, logistic multivariate regression analysis) with CWL ( $82 \%$ correctly predicted) (Table 4$)$.

Loss of taste/aversion was significantly $(p<0.05)$ present more frequently in patients with tumor sizes 3 and $4(11 \%$, $11 / 102)$ than in patients with tumor sizes 1 and $2(3 \%$, 4/143). Patients with tumor sizes 3 and 4 also reported significantly $(p<0.001)$ more frequent loss of appetite $(28 \%, 28 / 102)$ than patients with tumor sizes 1 and 2 $(5 \%, 7 / 143)$.

Finally, CWL was significantly $(p<0.001)$ present more frequently in patients with tumor sizes 3 and $4(43 \%, 46 / 107)$ than in patients with tumor sizes 1 and $2(7 \%, 12 / 159)$.

Table 2 Prevalence of critical weight loss per tumor localization

\begin{tabular}{lll}
\hline Tumor localization & \multicolumn{2}{l}{ Prevalence of critical weight loss } \\
\cline { 2 - 3 } & Percentage & Number \\
\hline Larynx & 12 & 18 \\
Supraglottic larynx & 34 & 13 \\
Glottic larynx & 3 & 3 \\
Sub-/transglottic larynx & 22 & 2 \\
Hypopharynx & 43 & 21 \\
Oropharynx/oral cavity & 34 & 23 \\
Nasopharynx & 36 & 5 \\
Other $^{\text {a }}$ & 8 & 10 \\
\hline
\end{tabular}

${ }^{a}$ Carcinoma in the ear, salivary gland, nose/paranasal cavity, esophagus, thyroid gland, skin, eye, lymphoma and unknown primary.

\section{Discussion}

In the current study, CWL was present in one fifth of all patients. Other studies in which CWL was assessed in head and neck cancer patients before treatment reported prevalences varying from $31 \%$ to $57 \%[17,19,28]$. Our lower prevalence may be explained by the timing of the assessment. In our study, CWL was assessed at the time of diagnosis, while patients in the other studies were assessed on starting radiotherapy or on the day before surgery. Initial surgery or radiotherapy is usually 2 to 6 weeks after diagnosis, while post-operative radiotherapy is usually 4 to 6 weeks after surgery. The extent of the weight loss may increase in the period between diagnosis and start of the treatment, specifically if dysphagia or passage difficulties are present.

Distribution of tumor localization in the current study differed from those reported in previous studies. In two of the three studies in which CWL was studied before treatment, significantly more patients with cancer in the oral cavity were included (respectively $10 \%$ and $43 \%$ instead of $1 \%$ in our study) $[17,19]$. In the other study, distribution of tumor localizations was not given [28]. In the UMCG, patients with cancer in the oral cavity are predominantly treated at the oral and maxillofacial surgery department and only a few of these patients are treated at the ENT department. This phenomenon may have resulted in an underestimation of the prevalence of CWL in head and neck cancer patients because patients with cancer in the oral cavity are at risk for CWL due to dysphagia and chewing problems. No information was given about the prevalence of CWL within the various tumor localizations in previous studies $[17,19,28]$. This information is relevant as we showed that prevalence of CWL varies greatly between various tumor localizations. Therefore, it is not known if differences in distribution of tumor localizations can explain the differences between total prevalences of CWL reported in the other studies.

In the current study, data were incomplete of only $9 \%$ of the patients. More data were incomplete in patients with a tumor in the hypopharynx, oropharynx/oral cavity and supraglottic larynx and in patients with T3/T4 tumors than in patients with tumors at the other localizations studied or with T1/T2 tumors. These tumor localizations and tumor sizes were identified in our study as risk factors for CWL. Although the differences between complete and incomplete data sets were significant for tumor site and tumor localization, the absolute numbers are small. As a result, the prevalence of CWL in the current study is slightly underestimated.

With regard to tumor localization, almost one third of the whole population was categorized as 'other' indicating cancer in the ear or nose or esophagus or salivary glands, 
Table 3 Reported symptoms per tumor localization

\begin{tabular}{|c|c|c|c|c|c|}
\hline & $\begin{array}{l}\text { Loss of } \\
\text { appetite } \\
\%^{\mathrm{a}}(n)\end{array}$ & $\begin{array}{l}\text { Loss of taste } \\
\text { and/or aversion } \\
\%^{\mathrm{a}}(n)\end{array}$ & $\begin{array}{l}\text { Dysphagia and/or } \\
\text { passage difficulties } \\
\%^{\mathrm{a}}(n)\end{array}$ & $\begin{array}{l}\text { Pain in } \\
\text { throat } \\
\%^{\mathrm{a}}(n)\end{array}$ & $\begin{array}{l}\text { Dry mouth and/or } \\
\text { pain in mouth } \\
\%^{\mathrm{a}}(n)\end{array}$ \\
\hline Larynx $(n=139)$ & $6(8)$ & $4(6)$ & $16(22)$ & $17(23)$ & $7(10)$ \\
\hline Supraglottic larynx $(n=34)$ & $12(4)$ & $9(3)$ & $47(16)$ & $47(16)$ & $12(4)$ \\
\hline Glottic larynx $(n=96)$ & $3(3)$ & $2(2)$ & $3(3)$ & $5(5)$ & $6(6)$ \\
\hline Sub-/transglottic larynx $(n=9)$ & $11(1)$ & $11(1)$ & $33(3)$ & $22(2)$ & $0(0)$ \\
\hline Hypopharynx $(n=47)$ & $23(11)$ & $9(4)$ & $62(29)$ & $47(22)$ & $15(7)$ \\
\hline Oropharynx and oral cavity $(n=66)$ & $29(19)$ & $9(6)$ & $53(35)$ & $38(25)$ & $15(10)$ \\
\hline Nasopharynx $(n=12)$ & $8(1)$ & $0(0)$ & $42(5)$ & $17(2)$ & $17(2)$ \\
\hline Other $^{\mathrm{b}}(n=109)$ & $11(12)$ & $6(6)$ & $14(15)$ & $9(10)$ & $6(7)$ \\
\hline
\end{tabular}

${ }^{\text {a }}$ Percentages are row percentages.

${ }^{\mathrm{b}}$ Carcinoma in the ear, salivary gland, nose/paranasal cavity, esophagus, thyroid gland, skin, eye, lymphoma and unknown primary.

etc. As expected, prevalence of CWL in this specific group was low $(8 \%)$ because the majority of these tumor localizations does not affect the swallowing function and therefore seldom leads to CWL, except for carcinoma in the esophagus. Only three patients with carcinoma in the esophagus were present in the current study, of which two had CWL. If the group categorized as 'other' was excluded from analysis, the prevalence of CWL in the remaining group of head and neck cancer patients increased to $24 \%$. In our opinion, patients with carcinoma in areas not directly localized in the upper digestive tract do not need to be screened routinely for CWL at the time of diagnosis.

CWL was present in almost one fifth of the patients. This prevalence may be lowered if the patient is already screened for CWL at the general practitioner. In The Netherlands, CWL during illness is generally poorly recognized and only half of the malnourished patients are referred to a dietitian [13]. More attention has to be put into screening in the general practitioner's office because a longer period of nutritional intervention may result in effective weight gain and a more positive effect on treatment-related morbidity and mortality.

Table 4 Logistic multivariate regression analysis on critical weight loss

\begin{tabular}{|c|c|c|c|c|}
\hline Variable & $\beta$ & $\begin{array}{l}\mathrm{SE} \\
\beta\end{array}$ & OR & $\begin{array}{l}95 \% \mathrm{CI} \text { of } \\
\text { OR }\end{array}$ \\
\hline Loss of appetite ${ }^{a}$ & 0.87 & 0.43 & 2.38 & $1.03-5.47$ \\
\hline Loss of taste and/or aversion ${ }^{a}$ & 1.33 & 0.64 & 3.80 & $1.08-13.36$ \\
\hline $\begin{array}{l}\text { Dysphagia and/or passage } \\
\text { difficulties }^{\mathrm{a}}\end{array}$ & 2.95 & 0.35 & 19.12 & $9.63-37.97$ \\
\hline Constant & -3.08 & 0.29 & 0.05 & $0.03-0.08$ \\
\hline
\end{tabular}

$\beta$ : regression coefficient, $S E \beta$ : standard error of $\beta, O R$ : odds ratio $=e^{\beta}$, $95 \%$ CI of OR: $95 \%$ confidence interval of odds ratio.

${ }^{\mathrm{a}}$ Absent or present.
Patients with a tumor in the hypopharynx, oropharynx/ oral cavity and supraglottic larynx had the highest risk for CWL, probably related to dysphagia, which was frequently present in these patient groups in the current study. About $34 \%$ of the patients with oral or oropharyngeal cancer report dysphagia before the start of the treatment [6]. Cancer in the glottic larynx rarely impairs swallowing function. Therefore, cancer in this localization is seldom associated with CWL as confirmed by the results of the current study. Prevalence of CWL was high $(36 \%)$ in patients with cancer in the nasopharynx. However, in our study, only 14 patients had nasopharyngeal cancer. The high prevalence might be the result of sample variation.

Loss of taste/aversion and loss of appetite were significantly associated with CWL in the logistic multivariate regression analysis. Loss of taste/aversion and loss of appetite may be symptoms of the cancer anorexia-cachexia syndrome $[12,21]$. This syndrome is the result of a multifactorial process involving cytokines, hormones and neuropeptides [15, 21, 22]. It was suggested that patients with head and neck cancer may have an elevated cytokine production related to tumor stage [20,23]. Future prospective studies should point out whether CWL at diagnosis is the result of starvation due to dysphagia and passage difficulties or the result of the systemic effects of the cancer anorexia-cachexia syndrome because the effectiveness of the nutritional intervention may depend on the underlying mechanisms of the weight loss.

The symptom 'pain in throat' was not significantly related to CWL. This finding may be the result of difficulty in distinguishing 'dysphagia' from 'pain in throat' by the observer or patient. These two symptoms overlap. The symptoms 'dry mouth and/or pain in mouth' were not significantly related to CWL either, possibly because the screening was performed at the time of diagnosis, whereas xerostomia is to be expected during and after treatment with radiotherapy or chemoradiation [30]. 
Prevalence of CWL was highest in patients with a tumor in the hypopharynx, oropharynx/oral cavity and supraglottic larynx, especially in patients with larger tumors. Nowadays, tumors with tumor size 3 and 4 are mainly treated with (accelerated) radiotherapy or chemoradiation. These treatment modalities are accompanied by dysphagia, odynophagia, xerostomia, taste disorders and loss of appetite. The results of our study have shown that most of these symptoms are predictive for CWL at the time of diagnosis. If no nutritional intervention takes place, body weight will further decline during cancer treatment. Prophylactic placement of a gastrostomy tube is effective in reducing weight loss during treatment with radiotherapy and chemoradiation $[11,16,24]$. When CWL is present at the time of diagnosis, placement of a gastrostomy tube in these patients in the period before the start of the treatment should be considered to optimize nutritional status.

CWL was dichotomized to be able to perform a risk analysis on clinically relevant weight loss. A gold standard for the assessment of malnutrition unfortunately does not exist currently. Weight loss is one of the criteria commonly used for assessment of the risk for malnutrition. Weight loss of $\geq 5 \%$ in 1 month or $\geq 10 \%$ in 6 months is a generally accepted cutoff for clinically relevant weight loss. Weight loss of $\geq 5 \%$ in 1 month or $\geq 10 \%$ in 6 months is associated with increased morbidity such as impaired wound healing, reduced immune function and decreased tolerance to surgery, radiotherapy and chemotherapy and with increased mortality $[2,25,28]$. Besides that, weight loss of $\geq 5 \%$ in 1 month or $\geq 10 \%$ in 6 months has a negative impact on disease-related quality of life and functional status [27]. The cutoff point used was adopted by ASPEN to define 'nutritionally at risk adults' [1].

In the current study, the patient was asked for his or her body weight. Generally, men overestimate body weight (mean $0.42 \mathrm{~kg}$ ), whereas women tend to underestimate their body weight (mean $1.41 \mathrm{~kg}$ ) [29]. This discrepancy is related to age. With an increase of age, more body weight is overestimated by men. Women tend to underestimate their weight less as age increases [14, 29]. In our study population, the majority (75\%) of patients was male and the median age in men was 64 years. Men in the age range of 60 to 69 years overestimate their weight with an average of $0.31 \mathrm{~kg}$ (SD $5.1 \mathrm{~kg}$ ) [14]. These findings indicate that the prevalence of CWL in the current study is probably slightly underestimated.

Although the UMCG H\&N CST is valuable, it was not validated yet. We used involuntary weight loss of $\geq 5 \%$ in 1 month or $\geq 10 \%$ in 6 months as the cutoff point for CWL because it appeared to be of great prognostic value in the occurrence of major post-operative complications and is associated with higher mortality and complication rate $[2$, $25,28]$. CWL is an indicator of recently developed malnutrition risk $[1,4]$. Chronic malnutrition risk can be detected by the body mass index (BMI, weight/height ${ }^{2}$ ) [26, 31]. Patients with head and neck cancer are at risk for chronic malnutrition as a result of bad dietary habits due to excessive drinking and smoking [3]. Therefore, the body mass index should be added to the screening tool in future studies.

In conclusion, $\mathrm{CWL}$ is already a considerable problem in head and neck cancer patients at the time of diagnosis. CWL is in particular frequently observed in patients with cancer in the hypopharynx, oropharynx/oral cavity and supraglottic larynx. Symptoms that were strongly related to CWL were dysphagia/passage difficulties, loss of taste/ aversion and loss of appetite.

\section{References}

1. ASPEN Board of Directors and Standards Committee (2005) Definition of terms, style, and conventions used in A.S.P.E.N. Guidelines and Standards. Nutr Clin Prac 20:281-285

2. Barbosa-Silva MC, Barros AJ (2005) Bioelectric impedance and individual characteristics as prognostic factors for post-operative complications. Clin Nutr 24(5):830-838

3. Bertrand PC, Piquet MA, Bordier I, Monnier P, Roulet M (2002) Preoperative nutritional support at home in head and neck cancer patients: from nutritional benefits to the prevention of the alcohol withdrawal syndrome. Curr Opin Clin Nutr Metab Care 5(4):435440

4. Blackburn GL, Bistrian BR, Maini BS, Schlamm HT, Smith MF (1977) Nutritional and metabolic assessment of the hospitalized patient. JPEN J Parenter Enteral Nutr 1(1):11-22

5. Brookes GB (1985) Nutritional status - a prognostic indicator in head and neck cancer. Otolaryngol Head Neck Surg 93(1):69-74

6. Colangelo LA, Logemann JA, Rademaker AW (2000) Tumor size and pretreatment speech and swallowing in patients with resectable tumors. Otolaryngol Head Neck Surg 122(5):653-661

7. de Faria PR, Cardoso SV, de A Nishioka S, Silva SJ, Loyola AM (2003) Clinical presentation of patients with oral squamous cell carcinoma when first seen by dentists or physicians in a teaching hospital in Brazil. Clin Oral Investig 7(1):46-51

8. Edington J, Boorman J, Durrant ER, Perkins A, Giffin CV, James R, Thomson JM, Oldroyd JC, Smith JC, Torrance AD, Blackshaw V, Green S, Hill CJ, Berry C, McKenzie C, Vicca N, Ward JE, Coles SJ (2000) Prevalence of malnutrition on admission to four hospitals in England. The Malnutrition Prevalence Group. Clin Nutr 19(3):191-195

9. Eisbruch A, Lyden T, Bradford CR, Dawson LA, Haxer MJ, Miller AE, Teknos TN, Chepeha DB, Hogikyan ND, Terrell JE, Wolf GT (2002) Objective assessment of swallowing dysfunction and aspiration after radiation concurrent with chemotherapy for head-and-neck cancer. Int J Radiat Oncol Biol Phys 53(1):23-28

10. Fang FM, Tsai WL, Chien CY, Chiu HC, Wang CJ, Chen HC, Hsiung CY (2005) Changing quality of life in patients with advanced head and neck cancer after primary radiotherapy or chemoradiation. Oncology 68(4-6):405-413

11. Fietkau R, Iro H, Sailer D, Sauer R (1991) Percutaneous endoscopically guided gastrostomy in patients with head and neck cancer. Recent Results Cancer Res 121:269-282

12. Hall JC (1979) The cachexia of cancer. Biomedicine 30(6):287291 
13. Kruizenga HM, Wierdsma NJ, van Bokhorst-de van der Schueren MA, Hollander HJ, Jonkers-Schuitema CF, van der Heijden E, Melis GC, van Staveren WA (2003) Screening of nutritional status in The Netherlands. Clin Nutr 22(2):147-152

14. Kuczmarski MF, Kuczmarski RJ, Najjar M (2001) Effects of age on validity of self-reported height, weight, and body mass index: findings from the Third National Health and Nutrition Examination Survey, 1988-1994. J Am Diet Assoc 101(1):28-34

15. Laviano A, Meguid MM, Rossi-Fanelli F (2003) Cancer anorexia: clinical implications, pathogenesis, and therapeutic strategies. Lancet Oncol 4(11):686-694

16. Lee JH, Machtay M, Unger LD, Weinstein GS, Weber RS, Chalian AA, Rosenthal DI (1998) Prophylactic gastrostomy tubes in patients undergoing intensive irradiation for cancer of the head and neck. Arch Otolaryngol Head Neck Surg 124(8):871-875

17. Lees J (1999) Incidence of weight loss in head and neck cancer patients on commencing radiotherapy treatment at a regional oncology centre. Eur J Cancer Care 8(3):133-136

18. Licitra L, Bernier J, Grandi C, Merlano M, Bruzzi P, Lefebvre JL (2002) Cancer of the oropharynx. Crit Rev Oncol Hematol 41 (1):107-122

19. Matthews TW, Lampe HB, Dragosz K (1995) Nutritional status in head and neck cancer patients. J Otolaryngol 24(2):87-91

20. Nakano Y, Kobayashi W, Sugai S, Kimura H, Yagihashi S (1999) Expression of tumor necrosis factor-alpha and interleukin-6 in oral squamous cell carcinoma. Jpn J Cancer Res 90(8):858-866

21. Plata-Salaman CR (2000) Central nervous system mechanisms contributing to the cachexia-anorexia syndrome. Nutrition 16 (10):1009-1012

22. Ramos EJ, Suzuki S, Marks D, Inui A, Asakawa A, Meguid MM (2004) Cancer anorexia-cachexia syndrome: cytokines and neuropeptides. Curr Opin Clin Nutr Metab Care 7(4):427-434
23. Riedel F, Zaiss I, Herzog D, Gotte K, Naim R, Hormann K (2005) Serum levels of interleukin-6 in patients with primary head and neck squamous cell carcinoma. Anticancer Res 25 (4):2761-2765

24. Scolapio JS, Spangler PR, Romano MM, McLaughlin MP, Salassa JR (2001) Prophylactic placement of gastrostomy feeding tubes before radiotherapy in patients with head and neck cancer: is it worthwhile? J Clin Gastroenterol 33(3):215-217

25. Seltzer MH, Slocum BA, Cataldi-Betcher EL, Fileti C, Gerson N (1982) Instant nutritional assessment: absolute weight loss and surgical mortality. JPEN J Parenter Enteral Nutr 6(3):218-221

26. Shetty PS, James WP (1994) Body mass index. A measure of chronic energy deficiency in adults. FAO Food Nutr Pap 56:1-57

27. van Bokhorst-de van der Schueren MA, Langendoen SI, Vondeling H, Kuik DJ, Quak JJ, van Leeuwen PA (2000) Perioperative enteral nutrition and quality of life of severely malnourished head and neck cancer patients: a randomized clinical trial. Clin Nutr 19 (6): $437-444$

28. van Bokhorst-de van der Schueren MA, van Leeuwen PA, Sauerwein HP, Kuik DJ, Snow GB, Quak JJ (1997) Assessment of malnutrition parameters in head and neck cancer and their relation to postoperative complications. Head Neck 19(5):419425

29. Villanueva EV (2001) The validity of self-reported weight in US adults: a population based cross-sectional study. BMC Public Health 1(1):11

30. Vissink A, Jansma J, Spijkervet FK, Burlage FR, Coppes RP (2003) Oral sequelae of head and neck radiotherapy. Crit Rev Oral Biol Med 14(3):199-212

31. World Health Organization (1995) Physical status: the use and interpretation of anthropometry. Report of a WHO Expert Committee No. 854 